Background: Systemic lupus erythematosus (SLE) is a systemic autoimmune disease, often presenting with neuropsychiatric manifestations. Reports on the frequency and patterns of these manifestations vary substantially and remain incompletely understood.

Objectives: We examined neuropsychiatric manifestations in the prospective nationwide cohort of Swiss SLE (SSCS) patients and conducted a systematic literature review to contextualise our findings.

Methods: We reviewed all patients included in the SSCS from 2007-2019 and classified severe neuropsychiatric manifestations. Searches were performed in relevant electronic databases from 1.1999-1.2020 and by checking reference lists of the pertinent literature. Authors of important papers were contacted to obtain further (unpublished) studies. We included prospective or cross-sectional studies focussing on neuropsychiatric manifestations in SLE, defined according the ACR criteria of 1999. Study selection and data extraction was made in duplicate. We secured salient study characteristics, composition of cohorts, the definitions and the frequencies of neuropsychiatric manifestations. We assessed heterogeneity across reports and investigated sources of variation using meta-regression models.

Results: The frequencies of severe manifestations found in the SSLE were $7.1 \%(49 / 688)$ for cerebrovascular events, $5.3 \%$ (37/688) for seizures and $6.5 \%$ $(45 / 688)$ for psychosis. The time-to-event analysis showed a linear relationship between duration of SLE and cumulative incidence of severe neuropsychiatric manifestations. Searches identified 530 studies and authors' contact yielded another unpublished report. We included 28 studies. The mean rates of the most commonly reported severe neuropsychiatric manifestations ranged in the magnitude of 50 percent points. Study characteristics and composition of cohorts could not explain heterogeneity of reported manifestation rates.

Conclusion: The spectrum of neuropsychiatric manifestations in SLE is widely dispersed. The diagnostic work-up and the reporting of manifestations varied substantially across studies which may explain inconsistencies to some extent. We call for concerted efforts and a broad consensus regarding stringent definitions of neuropsychiatric SLE manifestations that allow targeted detection, particularly with view to timely intervention and patient outcomes.

Disclosure of Interests: None declared

DOI: 10.1136/annrheumdis-2020-eular.1062

\section{AB0428 ASSOCIATION BETWEEN GEOGRAPHIC AND CLIMATOLOGICAL CONDITIONS AND CUTANEOUS MANIFESTATIONS IN LUPUS PATIENTS FROM THE SPANISH RHEUMATOLOGY SOCIETY LUPUS REGISTRY (RELESSER) AND ARGENTINE RHEUMATOLOGY SOCIETY LUPUS REGISTRY (RELESSAR) COHORT}

R. Menor-Almagro ${ }^{1}$, M. Argentina García ${ }^{2}$, I. Rua-Figueroa ${ }^{3}$, G. Pons Estel ${ }^{4}$, M. A. Martin-Martinez $z^{5}$ A. Muñoz Jimenez ${ }^{6}$, M. Galindo-Izquierdo ${ }^{7}$, J. Calvo-Alen $^{8}$, A. Fernandez-Nebro ${ }^{9}$, A. Olive ${ }^{10}$, B. Pons-Estel ${ }^{4}$, J. M. Pego-Reigosa ${ }^{11} .{ }^{1}$ Hospital de Jerez, Rheumatology, Jerez, Spain; ${ }^{2}$ HIGA San Martín, La Plata, Argentina; ${ }^{3} \mathrm{H}$. Dr. Negrín, Las Palmas de Gran Canaria, Spain; ${ }^{4} \mathrm{GO}-\mathrm{CREAR}$, Rosario, Argentina; ${ }^{5}$ Research Unit. SER, Madrid, Spain; ${ }^{6}$ H.U. Virgen del Rocío, Sevilla, Spain: ${ }^{7}$ H. 12 de Octubre, Madrid, Spain; ${ }^{8} \mathrm{H}$. de Araba, Alava, Spain; ${ }^{9} \mathrm{HU}$ Carlos Haya, Málaga, Spain; ${ }^{10} \mathrm{H}$. Trias i Pujol, Badalona, Spain; ${ }^{11} \mathrm{HCU}$ Vigo, Vigo, Spain

Background: Climatological conditions and ethnicity impact on the course of the disease in systemic lupus erythematosus patients.

Objectives: We carry out a study to analyze cutaneous manifestations in SLE patients from Argentina and Spain.

Methods: Patients data from Spanish Rheumatology Society Lupus Registry (RELESSER) and Argentina Rheumatology Society Lupus Registry (RELESSAR) were retrospectively analyzed for presence of cutaneous lesions (alopecia, photosensitivity, malar rash, discoid lesions, oral ulcers and subacute lesions). RELESSER-T and RELESSAR-T are multicenter, hospital-based registries, with retrospective cross-sectional collection of data about patients with SLE attending Spanish and Argentinian rheumatology services from the public national health system. Data about climatological conditions throughout the Spanish and Argentinian geography were provided by the Spanish Meteorological Agency and Argentine Meteorological Services. Results: A total of 5604 patients were included, median age $44.6 \pm 15.3,90.4$ $\%$ female. Current smokers were $28,9 \%$. Other climatological, geographical, biological and clinical data are shown in table 1. In the multivariable model, the presence of cutaneous lesion were significantly associated with temperature OR 1.116 (95\% Cl:1.042-1.196 p=0,002), altitude OR 1.001 (95\% Cl:1.000-1.001, $\mathrm{p}=0.012)$, hemolytic anemia OR $1.401(95 \% \mathrm{Cl}: 1.017-1.931 \mathrm{p}=0.039)$ and serositis OR 1.509 (95\% Cl:1.215-1.875 p=0.000). Negative associations were observed between females OR $0.392(95 \% \mathrm{Cl}: 0.297-0.518, \mathrm{p}=0.000)$, latitude OR 0.994 (95\% Cl:0.988-0.999, $\mathrm{p}=0.000)$, oceanic climate OR 0.566 (95\% Cl:0.381-0.842, $\mathrm{p}=0.005)$, leukopenia OR 0.790 (95\% Cl:0.643-0.970, $\mathrm{p}=0.025)$, renal disorder OR 0.761 (95\% Cl:0.600-0.966, $\mathrm{p}=0.025)$, glucocorticoids treatment OR 0.571
(95\% Cl:0.456-0.715, p=0.000) and antimalarial drugs OR 0.439 (95\% Cl:0.342$0.563, \mathrm{p}=0.000)$.

Table 1. Geographical, climatological and clinical/laboratory variables.

\begin{tabular}{|c|c|c|c|}
\hline & $\begin{array}{l}\text { No cutaneous } \\
\text { manifestations }\end{array}$ & $\begin{array}{c}\text { Cutaneous } \\
\text { manifestations }\end{array}$ & $\mathbf{p}$ \\
\hline Latitude, median (interqualite range) & 40.47 (38.35-41.63) & $40.37(-31.41-41.34)$ & 0.001 \\
\hline Altitude, median (interqualite range) & $192.0(37.0-698.0)$ & $156.0(25.0-609.0)$ & 0.000 \\
\hline Temperature, mean monthly \pm SD & $15.2 \pm 3.5$ & $15.3 \pm 3.6$ & 0.000 \\
\hline Humidity, mean monthly \pm SD & $66.9 \pm 7.2$ & $67.4 \pm 7.1$ & 0.108 \\
\hline Oceanic climate, n (\%) & $307(11)$ & $2406(89)$ & 0.000 \\
\hline Subhumid/altitude climate, $n(\%)$ & $17(7)$ & $240(93)$ & 0.002 \\
\hline Mediterranean climate, $\mathrm{n}(\%)$ & $292(17)$ & $1434(83)$ & 0.000 \\
\hline Arthritis, n (\%) & $523(12)$ & $3722(88)$ & 0,003 \\
\hline Serositis, n (\%) & $254(16)$ & $1368(84)$ & 0,000 \\
\hline Renal disorder, ever, n (\%) & $206(11)$ & $1576(89)$ & 0.015 \\
\hline Hemolytic anemia, n (\%) & $90(17)$ & $426(83)$ & 0,002 \\
\hline Leukopenia, n (\%) & $345(11)$ & 2669 (89) & 0.000 \\
\hline Thrombocytopenia, n (\%) & $170(15)$ & $986(85)$ & 0.076 \\
\hline Antiphospholipid antibodies, n (\%) & $293(15)$ & $1606(85)$ & 0.000 \\
\hline Anti DNA, $\mathrm{n}(\%)$ & $522(14)$ & $3279(86)$ & 0.044 \\
\hline Anti-Ro/SSA, n (\%) & $189(11)$ & $1563(89)$ & 0.000 \\
\hline Hypocomplementemia, n (\%) & $510(12)$ & $3736(88)$ & 0.000 \\
\hline $\begin{array}{l}\text { Glucocorticoids mucocutaneous } \\
\text { cause, ever, } \mathrm{n}(\%)\end{array}$ & $499(11)$ & $3928(89)$ & 0.000 \\
\hline Antimalarial drug: ever, $\mathrm{n}(\%)$ & $500(11)$ & $4034(89)$ & 0.000 \\
\hline
\end{tabular}

Conclusion: In the current analysis, taking RELESSAR and RELESSER data together, we observe positive association between higher temperature and skin lesion and negative association with living in southern hemisphere latitudes.

References: Influence of Solar Radiation in Cutaneous Manifestations of Lupus: Data from the Gladel Cohort [abstract]. Arthritis Rheumatol. 2016; 68 (suppl 10).

Disclosure of Interests: Raúl Menor-Almagro: None declared, Mercedes Argentina García: None declared, Iñigo Rua-Figueroa: None declared, Guillermo Pons Estel: None declared, Maria Auxiliadora Martin-Martinez: None declared, Alejandro Muñoz Jimenez.: None declared, María Galindo-Izquierdo: None declared, Jaime Calvo-Alen: None declared, Antonio Fernandez-Nebro: None declared, Alejandro Olive: None declared, Bernardo Pons-Estel Grant/research support from: GSK, Janssen, Consultant of: GSK, Janssen, Speakers bureau: GSK Janssen, Jose M Pego-Reigosa: None declared DOI: 10.1136/annrheumdis-2020-eular.3848

\section{AB0429 NEUTROPHIL TO LYMPHOCYTE RATIO INDEPENDENTLY PREDICTS CUTANEOUS MANIFESTATIONS IN PATIENTS WITH SJÖGREN'S SYNDROME}

A. Mihai ${ }^{1}$, D. Mardale ${ }^{1}$, D. Opris-Belinski ${ }^{2}$, R. Ionescu², C. Jurcut ${ }^{1}{ }^{1}$ " Dr. Carol Davila"Central Emergency University Military Hospital, Bucharest, Romania; 2"Sf. Maria"Clinical Hospital, "Carol Davila"University of Medicine and Pharmacy, Bucharest, Romania

Background: Various cutaneous manifestations are described in patients with Sjogren's syndrome (SS). However, the predictors for its occurrence are not fully investigated. Recently, data regarding the role of hematological parameters ratios in patients with rheumatic diseases were reported. However, routine hematological parameters and the derived ratios were not studied in SS patients.

Objectives: The aim of this study was to evaluate the predictors for cutaneous manifestations in a large cohort of patients with SS followed in a tertiary center. Methods: We included 114 patients with SS (mean age: $53.1 \pm 12.1 ; 94.7 \%$ female) We divided the patients in group A - patients with cutaneous manifestations and group B - without cutaneous manifestations. The complete laboratory workup [including the calculation of neutrophil to lymphocyte ratio (NLR), mean platelet volume (MPV) to platelet ratio, platelet distribution width (PDW) to platelet ratio] clinical manifestations and treatment were reviewed and the EULAR Sjögren's syndrome disease activity index (ESSDAI) was calculated for each patients.

Results: Cutaneous manifestations were diagnosed in 11 patients $(9.6 \%)$. The age of the patients, the levels of anti-SSA, complement, inflammatory markers (ESR, CRP), immunoglobulins and vitamin D levels, the ultrasonographic score of salivary glands and the ESSDAI value were similar in both groups. The patients with cutaneous manifestations were more frequently treated with hydroxychloroquine $(9 / 11 \mathrm{vs}$ $49 / 103, p=0.03$ ) but the mean doses were similar in both groups. The values of antiSSB were marginally higher in patients with cutaneous manifestations $(102.3 \pm 83.1$ vs $53.6 \pm 79.9, p=0.07$ ). The lymphocyte, neutrophil count, MPV and PDW were similar in both groups, while platelet count was lower in patients with cutaneous manifestations $(224090.9 \pm 59528.9$ vs $264339.8 \pm 60669.0, p=0.03)$. The MPV/PIt ratio tended to be higher in patients with cutaneous manifestations $(0.051 \pm 0.017$ 
vs. $0.043 \pm 0.013, p=0.07)$, but the values of PDW/PIt ratio $(0.064 \pm 0.022$ vs $0.051 \pm 0.018, p=0.03)$ and of NLR $(3.82 \pm 2.30$ vs $2.35 \pm 0.92, p=0.001)$ were found to be significantly higher in these patients. In multivariate analysis, only the NLR remains independently associated with cutaneous manifestations $(p=0.001)$. Using the ROC curve analysis, a cutoff of 2.70 for NLR had a $63 \%$ sensitivity and $69 \%$ specificity for cutaneous manifestations.

Conclusion: The hematological parameters related to platelets appear to be modified in patients with SS and cutaneous manifestations. However, only neutrophil to lymphocite ratio is independently associated with cutaneous involvement in these patients.

Disclosure of Interests: Ancuta MIHAI: None declared, DENISE MARDALE: None declared, Daniela Opris-Belinski Speakers bureau: as declared, Ruxandra Ionescu Consultant of: Consulting fees from Abbvie, Eli-Lilly, Novartis, Pfizer, Roche, Sandoz, Speakers bureau: Consulting and speaker fees from Abbvie, Eli-Lilly, Novartis, Pfizer, Roche, Sandoz, Ciprian Jurcut: None declared DOI: 10.1136/annrheumdis-2020-eular.2296

\section{AB0430 ERYTHEMATOSUS AND NEUROPSYCHIATRIC SYMPTOMS}

R. Monahan ${ }^{1}$, R. Fronczek ${ }^{2}$, J. Eikenboom ${ }^{3}$, H. Middelkoop ${ }^{2}$, L. J. J. Beaartvan de Voorde ${ }^{1}$, G. Terwindt ${ }^{2}$, N. Van der Wee ${ }^{4}$, F. Rosendaal ${ }^{5}$, T. Huizinga ${ }^{1}$, M. Kloppenburg ${ }^{1}$, G. M. Steup-Beekman ${ }^{1}$. 'Leiden University Medical Center, Rheumatology, Leiden, Netherlands; ${ }^{2}$ Leiden University Medical Center, Neurology, Leiden, Netherlands; ${ }^{3}$ Leiden University Medical Center, Internal Medicine, Division of Thrombosis and Hemostasis, Leiden, Netherlands; ${ }^{4}$ Leiden University Medical Center, Psychiatry, Leiden, Netherlands; ${ }^{5}$ Leiden University Medical Center, Clinical Epidemiology, Leiden, Netherlands

Background: Little is known about mortality in patients with systemic lupus erythematosus (SLE) presenting with neuropsychiatric (NP) symptoms.

Objectives: We aimed to evaluate all-cause and cause-specific mortality in patients with SLE and NP symptoms.

Methods: All patients with the clinical diagnosis of SLE of 18 years and older that visited the tertiary referral NPSLE clinic of the Leiden University Medical Center between 2007-2018 and signed informed consent were included in this study. Patients were classified as NPSLE if NP symptoms were attributed to SLE and immunosuppressive or anticoagulant therapy was initiated, otherwise patients were classified as non-NPSLE. Municipal registries were checked for current status (alive/deceased). Electronical medical files were studied for clinical characteristics and cause of death. Standardized mortality ratios (SMRs) and 95\% confidence intervals were calculated using data from the general Dutch population. In addition, a rate ratio (RR) was calculated using direct standardization to compare mortality in NPSLE with non-NPSLE patients.

Results: 351 patients with the clinical diagnosis of SLE were included, of which 149 patients were classified as NPSLE (42.5\%). Compared with the general population, mortality was increased five times in NPSLE (SMR 5.0, 95\% Cl: 2.68.5) and nearly four times in non-NPSLE patients (SMR 3.7, 95\% Cl: 2.2-6.0), as shown in Table 1. Risk of death due to cardiovascular disease (CVD) was increased in non-NPSLE patients (SMR 6.2, 95\% Cl:2.0-14.6) and an increased risk of death to infections was present in both NPSLE and non-NPSLE patients ((SMR 29.9, 95\% Cl: 3.5 - 105) and SMR 91.3 (95\% Cl: 18.8 - 266) respectively). However, mortality did not differ between NPSLE and non-NPSLE patients (RR $1.0,95 \% \mathrm{Cl}: 0.5-2.0)$

Table 1. All-cause mortality in SLE patients presenting with neuropsychiatric symptoms attributed to SLE (NPSLE) or to other causes (non-NPSLE)

\begin{tabular}{lcc}
\hline & NPSLE (N = 149) & Non-NPSLE (N = 202) \\
\hline Deaths (N, \%) & $13(8.7)$ & $17(8.4)$ \\
Age at death (median, range) & $49(32-79)$ & $59(20-89)$ \\
Follow-up time (years) & 906 & 1047 \\
Crude mortality rate (per 1000 PY) & 14.3 & 16.2 \\
All-cause mortality* & & $3.4(1.9-5.7)$ \\
Female & $5.5(2.8-9.6)$ & $6.2(1.3-18.2)$ \\
Male & $2.3(0.1-12.8)$ & $3.7(2.2-6.0)$ \\
Combined & $5.0(2.6-8.5)$ & \\
\hline
\end{tabular}

*Standardized mortality ratio, ratio of the observed and expected number of deaths

Conclusion: Mortality was increased in both NPSLE and non-NPSLE patients in comparison with the general population, but there was no difference in mortality between NPSLE and non-NPSLE patients. Risk of death due to infections was increased in both groups.

Disclosure of Interests: Rory Monahan: None declared, Rolf Fronczek: None declared, Jeroen Eikenboom: None declared, Huub Middelkoop: None declared, L.J.J. Beaart- van de Voorde: None declared, Gisela Terwindt: None declared, Nic van der Wee: None declared, Frits Rosendaal: None declared, Thomas Huizinga
Grant/research support from: Ablynx, Bristol-Myers Squibb, Roche, Sanofi, Consultant of: Ablynx, Bristol-Myers Squibb, Roche, Sanofi, Margreet Kloppenburg: None declared, G.M. Steup-Beekman: None declared

DOI: 10.1136/annrheumdis-2020-eular.939

\section{\begin{tabular}{|l|l}
\hline AB0431 SALIVARY GLAND ULTRASOUND IN CLINICAL \\
\hline
\end{tabular} PRACTICE}

F. Montero $^{1}$, K. Carpio ${ }^{1}$, I. Janta ${ }^{2}$, J. Molina Collada ${ }^{1}$, B. Serrano Benavente ${ }^{1}$,

J. Martínez-Barrio ${ }^{1}$, A. Ariza ${ }^{1}$, J. Rivera ${ }^{1}$, C. Gonzalez ${ }^{1}$, I. Monteagudo ${ }^{1}$, J.

C. Nieto ${ }^{1} .{ }^{1}$ Gregorio Marañón Hospital, Madrid, Spain; ${ }^{2}$ University Clinical

Hospital of Valladolid, Valladolid, Spain

Background: Sjogren's syndrome (SS) is characterized by lymphocytic infiltration of the exocrine glands and marked B-lymphocytic cell hyperreactivity involving a variety of serum autoantibodies. ${ }^{1}$ Salivary Gland Ultrasound (SGU) is a simple, fast, and well- tolerated examination, wich provides information about glandular structure and has proven to be very useful in the Sjögren Syndrome diagnosis $^{2}$. A prognostic value has also been proposed due to its posible relationship with lymphomas and extra-glandular manifestations.

Objectives: The objective of our study is to evaluate ultrasound results in patients who went through an SGU in clinical practice, its usefulness in the diagnosis of Sjögren's syndrome and the presence of complications (lymphomas extra-glandular manifestations or factors related to increased lymphoma risk).

Methods: We conducted a retrospective cross-sectional study with review of clinical records that included all those patients coded as SGU in the Ultrasound unit of Rheumatology Department from 2016 to December 2019. Information collected included final diagnosis, laboratory results clinical manifestations and ultrasound results. We performed an analysis on the frequency of pathological SGU and on the relationship between this lesions in patients with final SS diagnosis and the presence of lymphoma, extra-glandular manifestations and the laboratory values related with increased lymphoma risk (low complement levels, cryoglobulinemia, positive autoimmunity)

Results: SGU was performed in 171 patients in four years, 162 women (94.7\%). The previous diagnoses, reason for the request and final diagnosis are shown in Table 1. The vast majority of the SGU were normal, only $28(16,3 \%)$ were pathological, 13 with a grade II and 8 with a grade III. In the other 7 patients grading was not available. Of the 28 patients with pathological SGU, none had lymphoma, only 3 had recurrent parotitis and 15 had had extra-glandular manifestations, mainly arthralgia / arthritis (12). Only 1 patient, with rheumatoid arthritis, had had a lymphoma and the SGU was normal. Antibody positivity was frequent in pathological SGU, 16/23 antinuclear antibodies, 13/22 anti-Ro and $9 / 23$ rheumatoid factor. Of the 86 patients without previous diagnosis, 18 were diagnosed with Sjogren syndrome, 9 with pathological SGU and the rest were normal. No patient diagnosed with a dry non-autoimmune syndrome presented pathological SGU.

Table 1. Previous diagnoses, reason for request and final diagnoses.

\begin{tabular}{|c|c|c|}
\hline Previous diagnoses ( $\mathrm{n}: 171$ ) & Reason for request (n: 171) & $\begin{array}{l}\text { Final diagnosis } \\
\text { (n: 78) }\end{array}$ \\
\hline Without prior diagnosis ( $\mathrm{n}: 86$ ) & $\begin{array}{l}\text { Dry non- autoinmune syndrome } \\
\qquad(\mathrm{n}: 127)\end{array}$ & $\begin{array}{l}\text { Dry non-autoim- } \\
\text { mune syndrome } \\
\text { (n: } 60)\end{array}$ \\
\hline Primary Sjögren's syndrome (n: 11) & Primary Sjögren's syndrome (n: 12) & $\begin{array}{l}\text { Primary Sjögren's } \\
\text { syndrome (n: 18) }\end{array}$ \\
\hline $\begin{array}{l}\text { Systemic Lupus Erythematosus } \\
\text { (n: } 9)\end{array}$ & Lymphoma (n: 0) & $\begin{array}{l}\text { Secondary Sjögren's } \\
\text { syndrome (n: } 0)\end{array}$ \\
\hline Rheumatoid arthritis (n: 24) & Control (n: 13) & $\begin{array}{c}\text { Other diagnoses } \\
(\mathrm{n}: 7)\end{array}$ \\
\hline Other diagnoses (n: 18) & Other reasons ( $n: 11)$ & \\
\hline
\end{tabular}

Conclusion: The impact of the SGU is low and its use cannot, for now, displace other methods (e.g. salivary gland biopsy) in the diagnosis of SS. Also our low number of patients with pathological SGU together with the low prevalence of the complications studied (e.g. lymphomas $=1$ ) prevents the expected comparisons References:

[1] Ramos-Casals M, Solans R, Rosas J, et al. Primary Sjogren syndrome in Spain: clinical and immunologic expression in 1010 patients. Medicine (Baltimore) 2008; 87: 210-219.

[2] Damjanov N, Milic V, Nieto-Gonzalez JC, et al. Multiobserver Reliability of Ultrasound Assessment of Salivary Glands in Patients with Established Primary Sjogren Syndrome. J Rheumatology 2016; 43: 1858-1863.

Disclosure of Interests: Fernando Montero: None declared, Karen Carpio: None declared, lustina Janta: None declared, Juan Molina Collada: None declared, Belén Serrano Benavente: None declared, Julia Martínez-Barrio Consultant of: UCB Pharma, Alfonso Ariza: None declared, Javier Rivera: None declared, Carlos Gonzalez Consultant of: Gilead, Janssen, Novartis,, Speakers 